\title{
Fruit By-Product Processing and Bioactive Compounds
}

\author{
Mohammed Saleh $\mathbb{D}^{1},{ }^{1}$ Lana Amro, ${ }^{1}$ Haya Barakat, ${ }^{1}$ Rahma Baker, ${ }^{1}$ Amani Abu Reyash, \\ Reham Amro, ${ }^{1}$ and Jihad Qasem ${ }^{2}$
}

${ }^{1}$ Department of Nutrition and Food Technology, The University of Jordan, Amman 11942, Jordan

${ }^{2}$ Department of Food Technology, Alquds University, Jerusalem, State of Palestine

Correspondence should be addressed to Mohammed Saleh; misaleh@ju.edu.jo

Received 19 July 2021; Revised 26 August 2021; Accepted 2 September 2021; Published 13 September 2021

Academic Editor: Antimo Di Maro

Copyright @ 2021 Mohammed Saleh et al. This is an open access article distributed under the Creative Commons Attribution License, which permits unrestricted use, distribution, and reproduction in any medium, provided the original work is properly cited.

\begin{abstract}
Total phenolic content (TPC), total flavonoid content (TFC), ferric reducing antioxidant potential (FRAP), and diphenyl-1picrylhydrazyl (DPPH) free radical scavenging activity of avocado peel, avocado seeds, kiwi fruit, orange peel, pineapple peel, and pomegranate skin by-products during processing (i.e., dried, blanched, freezed, and fresh) were determined. It was hypothesized that fruit by-products would add a significant value to the food products. Heat treatments resulted in increasing TPC and TFC and reducing power of fruit by-products with avocado peels TFC of 136.9 and $63.1 \mathrm{mg} / 100 \mathrm{~g}$ of dried and blanched treatments, respectively, compared to $14.4 \mathrm{mg} / 100 \mathrm{~g}$ of fresh and $20.6 \mathrm{mg} / 100 \mathrm{~g}$ of freezed treatments. Orange peels TFC increased from $54.4 \mathrm{mg} / 100 \mathrm{~g}$ of fresh to 194.4 and $380.0 \mathrm{mg} / 100 \mathrm{~g}$ for blanched and dried treatments, respectively. Fresh treatments had the lowest $\mathrm{DPPH}(\%)\left(\mathrm{IC}_{50}\right)$, indicating a significant effect of blanching and drying on fruit by-product antioxidant activity with some exceptions. $\mathrm{IC}_{50}$ increased from 20.0 of fresh to $39.8 \%$ of dried pineapple peel and from 6.5 to $15.0 \%$ for pomegranate skin of fresh and dried treatments, respectively. The use of fruit by-products regardless to its processing as supplements to flours would significantly increase flour's bioactive availability.
\end{abstract}

\section{Introduction}

The consumptions of synthetic additives such as antioxidants in foods are increasingly limited due to concerns of potential adverse effects on human health [1]. Natural antioxidants are of vital importance as a health concern of potential risks of synthetic antioxidants in the food industry. The beneficial health attributes of the natural bioactive compounds include having antibacterial, antitumor, antiviral, antimutagenic, and cardioprotective activities [2].

Fresh fruits and vegetables intake in the human diet is increasing in both domestic and international levels due to growing recognition of its health-promoting benefits $[3,4]$. Fresh fruits and vegetables are rich sources of the natural antioxidants such as phenolic compounds. For instance, mango and pomegranates were reported to have a radical scavenging activity comparable to that of butylated hydroxyanisole (BHA) [5]. El-Barotyet al. [6] on the same manner studied the probiotic and antioxidant activities of pineapple and reported a $0.3-1.4 \log$ cycle increases in probiotic and a significant increase in antioxidant activities as a result of pineapple powder supplementation in yoghurt. Hui et al. [7] reported that peanut skins in addition of $2.5 \%$ to cookies resulted in $30 \%$ increase in polyphenolic content.

In the plant kingdom, phenolic compounds are the most widely distributed secondary metabolites that contribute to both plant and human health. Polyphenols such as flavonoids play numerous molecular and biochemical roles in plant, such as signaling, plant defense, mediating auxin transport, antioxidant activity, and free radical scavenging $[8,9]$ Fruits are typically consumed in fresh or in a processed form, and the peel of the fruit is discarded as waste of little value. Since these fruits' residues are inexpensive and easily available, it is usually used as fertilizers [10]. However, studies indicated that significant amounts of bioactive compounds and essential nutrients are present in the seeds, peels, and skins of the fruits [11]. Therefore, its antioxidants activity and bioactive molecules content limited focus has 
been shifted to such residues as valuable constituents in the food, cosmetics, and pharmaceutical industries [4].

Fruit by-products are considered a rich source of dietary fibers, organic acids, minerals, pigments, and phenolic compounds [4]. Avocado (Persea americana) seeds, for example, contain more than $70 \%$ of the amino acids of the fruit and possess significant amounts of antioxidant activity [12]. Kiwifruit (Actinidia deliciosa) and pomegranate (Punica granatum L.) skins also considered a significant source of antioxidants [12]. Despite its bioactive compound contents, fruit by-products are prone to either spoilage or producing objectionable flavor and taste due to the greater microbial content and organic content [13]. Therefore, fruit by-products are required to be processed before use in food applications.

Although processing can impart foods with its distinctive characteristics including texture, flavor, and aroma; it also can cause a reduction in their bioactive compounds, nutrient contents, and antioxidant capacity $[14,15]$. Due to the lack of information regarding the effects processing on the bioactive compounds of fruits by-products, this study was undertaken to assess the effects of blanching, freezing, and drying on TFC and TPC and antioxidant activities on fruits by-products.

\section{Materials and Methods}

2.1. Materials. Avocado (Persea americana) (i.e., seed and skin), kiwifruit (Actinidia deliciosa) (i.e., skin), pineapple (Ananas comosus) (i.e., peel) pomegranate (Punica granatum L.) (i.e., skin), and orange peel (Citrus sinensis) were acquired from a local fruit and salad manufacturer in Amman, Jordan. The study was conducted in 2019, and all fruit by-products were collected using fresh (i.e., grown and harvested in Jordan) or imported fruits.

Folin-Ciocalteu reagent was acquired from AppliChem, GmbH (Darmstadt, Germany). 2-Chloro-p-nitrophenyl$\alpha$-D-maltotrioside, quercetin, gallic acid, ascorbic acid, and aluminum trichloride were from Sigma-Aldrich (Steinheim, Germany), 2, 2-Diphenyl-1-picrylhydrazyl was obtained from ICN, Biomedical Inc., USA. Sodium carbonate was purchased from Merck (Darmstadt, Germany). All solvents used were of HPLC grade.

2.2. Treatments and Extraction. Fruit by-product samples were kept cold (i.e., $8^{\circ} \mathrm{C}$ ) until transferred to the laboratories of the Department of Nutrition and Food Technology, the University of Jordan. Samples were freshly prepared, as arrived to the department's laboratories, and were sliced divided into four sections separated by treatments (i.e., fresh, blanched, frozen, and dried). Complete randomized design (CRD) was followed in conducting the study. Fresh samples were not treated. Blanched samples were immured in $80^{\circ} \mathrm{C}$ water for $4 \mathrm{~min}$ after which the blanching water was evaporated, and the residues were added to the treated fruit by-products. For freezing treatment, samples were kept at $-18^{\circ} \mathrm{C}$ for 14 days before samples were prepared for extraction and measurements, and for drying treatment, sliced samples were dried using a conventional oven at $45^{\circ} \mathrm{C}$ for up to 48 hours. Blanched, fresh, frozen, and dried treatments moisture contents were adjusted to $12 \%$ moisture content before extraction in order to eliminate the effect of water extraction solution polarity as affected by moisture content of the samples. Treated fruit by-products were then grinded separately into flour to pass through a $100 \mu \mathrm{m}$ sieve.

For extractions, $40 \mathrm{ml}$ of ethanol was added to $10 \mathrm{~g}$ of samples, vortexed for 30 minutes before filtered three times. The filtrate from the first, second, and third extracts were combined and kept at refrigerated temperature (i.e., $7^{\circ} \mathrm{C}$ ) until use.

2.3. Total Flavonoids Content (TFC) Determination. TFC of the fruit by-product extracts were determined by according to the method reported by Phjimulyani et al. [16]. In brief, $0.5 \mathrm{ml}$ of each extract as well as the standard (quercetin) was mixed with $1 \mathrm{ml}$ of $2 \%$ aluminum trichloride/ethanol solution. The volume of the mixture was then completed to $25 \mathrm{ml}$ with water in a volumetric flask and allowed to stand for $40 \mathrm{~min}$ at $23.2^{\circ} \mathrm{C}$. Absorbance of the sample was then measured at $415 \mathrm{~nm}$ using the spectrophotometer (Labomed spectrophotometer, model UVD-2900, Labomed, USA). Results were expressed in $\mathrm{mg}$ of quercetin equivalent per $100 \mathrm{~g}$ dry weight plant material. Figure 1 shows the standard curve of quercetin equivalent that was used to calculate TFC of fruit by-products.

\subsection{Total Phenolic Content (TPC) Determination. TPC of the} fruit by-product extracts was determined by the Folin-Ciocalteu reagent (FCR) according to Miliauskas et al. [17]. In summary, $0.1 \mathrm{ml}$ ethanol extracts and standard solution (gallic acid) were separately mixed with $0.5 \mathrm{ml}$ of Folin-Ciocalteu reagent. After exactly $3 \mathrm{~min}, 2 \mathrm{ml}$ of $10 \%$ (w/ v) sodium carbonate solution was added before the final mixture was vortex for 20 seconds and then incubated in dark for $1 \mathrm{~h}$ at $23.2^{\circ} \mathrm{C}$. Absorbance was then measured at $650 \mathrm{~nm}$ using the spectrophotometer (Labomed spectrophotometer, model UVD-2900, Labomed, USA). Results were expressed in $\mathrm{mg}$ gallic acid equivalents per $100 \mathrm{~g}$ dry weight plant material. Figure 1 shows the standard curve of gallic acid equivalent that was used to calculate TPC of fruit by-products.

2.5. Ferric Reducing Antioxidant Potential (FRAP) Determination. Reducing antioxidant potential of fruit byproducts was determined using the following method that was described by Benzie and Strain [18]. In brief, FRAP reagent was prepared from $300 \mathrm{mmoL} / \mathrm{L}$ acetate buffer, $\mathrm{pH}$ 3.6, $20 \mathrm{mmoL} / \mathrm{L}$ ferric chloride, and $10 \mathrm{mmoL} / \mathrm{L}$ TPTZ made up in $40 \mathrm{mmoL} / \mathrm{L}$ hydrochloric acid. The solutions were mixed together in the ratio $10: 1: 1(\mathrm{v}: \mathrm{v}: \mathrm{v})$, respectively. $3 \mathrm{~mL}$ of FRAP reagent was then mixed with $50 \mu \mathrm{L}$ of fruit byproducts extract, and the contents were mixed thoroughly. After 30 minutes incubation at $23.2^{\circ} \mathrm{C}$, absorbance of the samples was measured $593 \mathrm{~nm}$ at $30 \mathrm{~s}$ intervals for 4 minutes. Result was expressed as ascorbic acid equivalent ( $0.1 \mathrm{~g}$ of dry sample material $/ 100 \mathrm{ml}$ distilled water). Figure 1 presents 

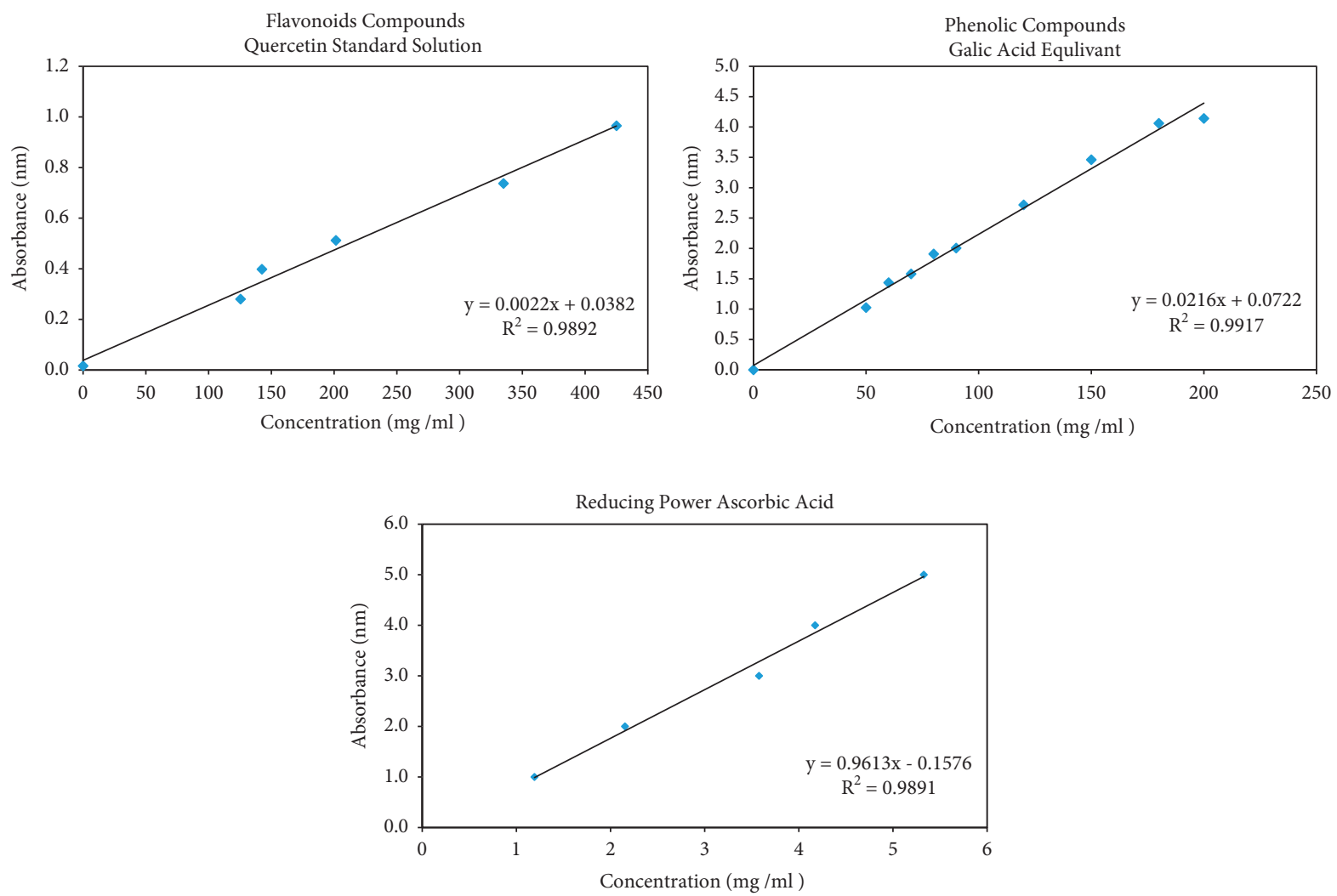

FIGURE 1: Standars curves used to calculate flavonoids, phenolic contents, and reducing power of dried, blanched, freezed, and fresh fruit byproducts.

the standard curve of ascorbic acid equivalent that was used to calculate reducing activity of fruit by-products.

\subsection{Diphenyl-1-picrryylhydazyl (DPPH) Free Radical Scav-} enging Activity Determination. DPPH radical scavenging effect was determined according to the method of Miliauskas et al. [17]. In brief, $0.2 \mathrm{ml}$ of ethanol solution of DPPH $(2,2-$ diphenyl-1- picrylhydrazyl) $(50 \mathrm{mg} / 100 \mathrm{ml})$ was mixed in selected levels of fruit by-product extract solutions. The mixture was then brought to a total volume of $4.0 \mathrm{ml}$ with ethanol. After mixing thoroughly, the mixture was allowed to stand for $45 \mathrm{~min}$ in a dark place. Absorbance was then measured at $515 \mathrm{~nm}$, and the radical scavenging activity of the tested samples was expressed as \% inhibition according to the following formula [19].

$$
\text { Inhibition }(\%)=\left[\frac{(\text { Abs. control }- \text { Abs. sample })}{\text { Abs. control }}\right] \times 100 \text {. }
$$

$\mathrm{IC}_{50}$ was calculated as the concentration of each extract $(\mathrm{mg} / \mathrm{ml})$ needed to scavenge $50 \%$ of the DPPH radicals with a lower IC50 indicating a higher antioxidant activity of a compound (Figure 2).

2.7. Statistical Analysis. Flavonoids (mg/100 g), phenolics $(\mathrm{mg} / 100 \mathrm{~g})$, reducing power (\%), and DPPH inhibition measurements of processed avocado peel, avocado seeds, kiwi fruit, orange peel, pineapple peel, and pomegranate skin by-products were averaged and regarded as a replicate. Analysis of variance (ANOVA) of the complete randomized design (CRD) was performed to determine the significance of differences using JMP (release 10.0, SAS Institute, Cary, NC). Least significant differences (LSDs) at the $5 \%$ level of probability were used to separate differences in TFC, TPC, reducing power $(0.1 \mathrm{~g} / 100 \mathrm{ml})$, and $\mathrm{DPPH}$ inhibition (\%) between treatments of the same fruit by-products as well as to separate these differences of the same treatment between fruit by-products.

\section{Results and Discussion}

Table 1 provides the average TFC $(\mathrm{mg} / 100 \mathrm{~g})$, TPC $(\mathrm{mg} /$ $100 \mathrm{~g})$, reducing power $(0.1 \mathrm{~g} / 100 \mathrm{ml})$, and $\mathrm{DPPH}$ inhibition (\%) of avocado peel, avocado seeds, kiwi fruit, orange peel, pineapple peel, and pomegranate skin by-products during processing. The ANOVA indicated a significant difference $(P<0.05)$ between various processing methods of TFC and TPC measurements of fruit by-products (data not shown). More specifically, the results illustrated an increase in TFC and TPC of dried and blanched fruit by-products in comparison with fresh and freezed treatments. Dried treatments had the greatest TFC and TPC. For example, avocado peels TFC increased from $14.4 \mathrm{mg} / 100 \mathrm{~g}$ of fresh to $20.6,63.1$, and $136.9 \mathrm{mg} / 100 \mathrm{~g}$ for freezed, blanched, and dried, respectively. Similarly, orange peels TFC increased from $54.4 \mathrm{mg} / 100 \mathrm{~g}$ of fresh to $56.9,194.4$, and $380.0 \mathrm{mg} / 100 \mathrm{~g}$ for frozen, blanched, 

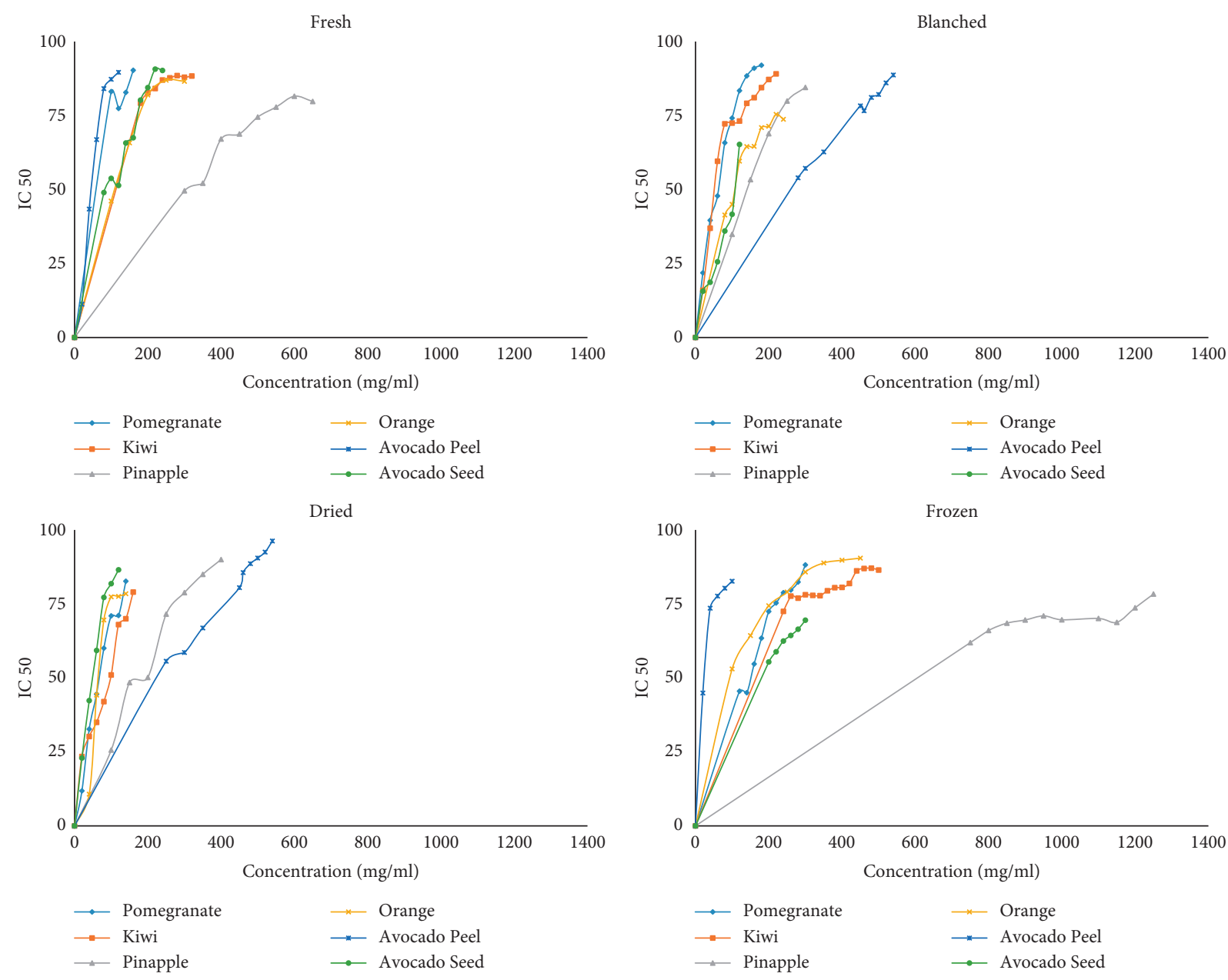

FIGURE 2: Diphenyl-1-picrylhydrazyl (DPPH) free radical scavenging activity of dried, blanched, freezed, and fresh fruit by-products.

TABLE 1: Means of total flavonoid content (TFC, $\mathrm{mg} / 100 \mathrm{~g}$ ), total phenolic content (TPC, $\mathrm{mg} / 100 \mathrm{~g}$ ), reducing power (FRAP <0.1 g/100 ml), and DPPH inhibition (IC50, \%) of avocado peel, avocado seeds, kiwi fruit, orange peel, pineapple peel, and pomegranate skin during processing.

\begin{tabular}{|c|c|c|c|c|c|}
\hline Fruit by-product & TRT & TFC $(\mathrm{mg} / 100 \mathrm{~g})^{1}$ & TPC $(\mathrm{mg} / 100 \mathrm{~g})$ & FRAP $(0.1 \mathrm{mg} / 100 \mathrm{ml})$ & $\mathrm{IC}_{50}(\%)$ \\
\hline \multirow{4}{*}{ Avocado peel } & Dried & $136.9^{\mathrm{a}}$ & $1,017.2^{\mathrm{b}}$ & $93.6^{\mathrm{d}}$ & $14.5^{\mathrm{c}}$ \\
\hline & Blanched & $63.1^{\mathrm{b}}$ & $359.1^{\mathrm{d}}$ & $169.0^{\mathrm{a}}$ & $11.1^{\mathrm{d}}$ \\
\hline & Frozen & $20.6^{\mathrm{c}}$ & $1,000.5^{\mathrm{c}}$ & $128.3^{\mathrm{c}}$ & $55.6^{\mathrm{b}}$ \\
\hline & Fresh & $14.4^{\mathrm{d}}$ & $2,466.8^{\mathrm{a}}$ & $149.2^{\mathrm{b}}$ & $76.6^{\mathrm{a}}$ \\
\hline \multirow{4}{*}{ Avocado seed } & Dried & $54.1^{\mathrm{a}}$ & $5,973.0^{\mathrm{a}}$ & $152.2^{\mathrm{a}}$ & $52.5^{\mathrm{a}}$ \\
\hline & Blanched & $45.4^{\mathrm{b}}$ & $4,958.6^{\mathrm{b}}$ & $147.9^{\mathrm{b}}$ & $21.6^{\mathrm{c}}$ \\
\hline & Frozen & $33.8^{\mathrm{d}}$ & $1,268.6^{\mathrm{d}}$ & $128.2^{\mathrm{d}}$ & $28.2^{\mathrm{b}}$ \\
\hline & Fresh & $39.8^{\mathrm{c}}$ & $2,036.6^{\mathrm{c}}$ & $142.7^{\mathrm{c}}$ & $17.8^{\mathrm{d}}$ \\
\hline \multirow{4}{*}{ Kiwi fruit } & Dried & $10.6^{\mathrm{a}}$ & $4,571.9^{\mathrm{a}}$ & $59.9^{\mathrm{b}}$ & $32.1^{\mathrm{b}}$ \\
\hline & Blanched & $1.3^{\mathrm{b}}$ & $852.6^{\mathrm{b}}$ & $93.6^{\mathrm{a}}$ & $43.2^{\mathrm{a}}$ \\
\hline & Frozen & $0.0^{\mathrm{c}}$ & $324.2^{c}$ & $32.1^{\mathrm{c}}$ & $30.0^{c}$ \\
\hline & Fresh & $1.3^{\mathrm{b}}$ & $331.8^{\mathrm{c}}$ & $28.5^{\mathrm{d}}$ & $20.2^{\mathrm{d}}$ \\
\hline \multirow{4}{*}{ Orange peel } & Dried & $380.0^{\mathrm{a}}$ & $4,232.3^{\mathrm{a}}$ & $177.7^{\mathrm{a}}$ & $27.7^{\mathrm{b}}$ \\
\hline & Blanched & $194.4^{\mathrm{b}}$ & $2,445.5^{\mathrm{b}}$ & $133.9^{\mathrm{b}}$ & $38.8^{\mathrm{a}}$ \\
\hline & Frozen & $56.9^{c}$ & $828.5^{\mathrm{c}}$ & $49.3^{c}$ & $26.1^{\mathrm{b}}$ \\
\hline & Fresh & $54.4^{\mathrm{c}}$ & $756.5^{\mathrm{c}}$ & $47.7^{\mathrm{d}}$ & $26.2^{\mathrm{b}}$ \\
\hline
\end{tabular}


TABLE 1: Continued.

\begin{tabular}{|c|c|c|c|c|c|}
\hline Fruit by-product & TRT & TFC $(\mathrm{mg} / 100 \mathrm{~g})^{1}$ & TPC (mg/100 g) & FRAP $(0.1 \mathrm{mg} / 100 \mathrm{ml})$ & $\mathrm{IC}_{50}(\%)$ \\
\hline \multirow{4}{*}{ Pineapple peel } & Dried & $18.8^{\mathrm{a}}$ & $1,342.8$ & $42.6^{\mathrm{a}}$ & $15.0^{\mathrm{b}}$ \\
\hline & Blanched & $13.1^{\mathrm{b}}$ & $733.4^{\mathrm{b}}$ & $32.3^{\mathrm{b}}$ & $19.8^{\mathrm{a}}$ \\
\hline & Frozen & $1.3^{\mathrm{c}}$ & $152.4^{\mathrm{c}}$ & $6.5^{\mathrm{c}}$ & $9.9^{c}$ \\
\hline & Fresh & $18.8^{\mathrm{a}}$ & $95.0^{\mathrm{d}}$ & $0.6^{\mathrm{d}}$ & $6.5^{\mathrm{d}}$ \\
\hline \multirow{4}{*}{ Pomegranate skin } & Dried & $862.5^{\mathrm{a}}$ & $6,138.2^{c}$ & $93.6^{\mathrm{d}}$ & $39.8^{c}$ \\
\hline & Blanched & $405.6^{\mathrm{d}}$ & $5,346.8^{\mathrm{d}}$ & $106.3^{\mathrm{c}}$ & $45.3^{\mathrm{b}}$ \\
\hline & Frozen & $478.8^{\mathrm{c}}$ & $6,454.4^{\mathrm{b}}$ & $173.5^{\mathrm{a}}$ & $47.8^{\mathrm{a}}$ \\
\hline & Fresh & $504.4^{\mathrm{b}}$ & $6,909.8^{\mathrm{a}}$ & $166.6^{\mathrm{b}}$ & $20.0^{\mathrm{d}}$ \\
\hline
\end{tabular}

${ }^{1}$ Flavonoids content ((quercetin equivalents (mg/100 g)), phenolic compounds (gallic acid equivalents (mg/100 g)), FRAP (ascorbic acid equivalent (0.1 g/100 ml)), and $\mathrm{IC}_{50}$ (i.e., concentration of extract $(\mathrm{mg} / \mathrm{ml})$ needed to scavenge $50 \%$ of the DPPH radicals $\left.(\mathrm{mg} / \mathrm{ml})\right)$ within the same fruit by-product and different treatment having different letters are significantly $(P<0.05)$ different according to the LSD.

and dried, respectively. The trend of reducing power of fruit by-products, however, was not consistent for avocado and pomegranate where fresh and freezed treatments had higher reducing powers than either the blanched or dried treatments. Pomegranate fruits are recognized for their high anthocyanin content accumulation in the skin and arils $[20,21]$. Our results agree with Brand-Williams et al. [22] who reported high levels of bioactive compounds in avocado husk and with seed showing high levels of these compounds.

TFC and TPC after blanching were greater than that of the fresh and freezed treatments, which may be ralted to the efficient release of bioactive compounds from the fruit byproduct's matrix by softening the cells. Furthermore, the bioaccessibility of phenolic compounds may also be increased due to heat treatment releasing the bound phenolic compounds. Thermal processing (i.e., blanching, boiling, and/or steaming) was reported to an increase in TPC of vegetables and fruits after heat treatments; a result related to the breaking down of bioactive compounds results in increased TFC and TPC [23]. On the same manner, blanching was reported to increase total phenolic and carotenoid contents of the carrots [24]. Al-Dabbas et al. [25] reported an increase in TFC and TPC and antioxidant activity of sweet and chilli pepper with heat treatment. The authors attributed the increase of bioactive compounds during heating to the dehydration of food matrix that led to the improvement in extractability of phenolics. Shaimaa et al. [26], on the other hand, related cooling to the inhibition of polyphenolics degradation as a result of inactivating polyphenol oxidase enzyme during heating.

Reducing power and DPPH inhibition of fruit byproducts treatments are also presented in Table 1. Reducing power (\%) of orange peel had the greatest value to $177.7(\%)$. Results also indicated that blanched and dried treatments had the greatest reducing power among fruit by-product treatments except pomegranate skin. Freezed pomegranate skin had a reducing power of $173.5 \%$ compared to 166.6 , 106.3 , and $93.6 \%$ of fresh, blanched, and dried treatments, respectively. The increased antioxidant activity of the fruit by-products extracts probably due to the polarity of the extract solution. The increased antioxidant activity of the fruit by-products extracts indicated an increased capacity of these extracts to reduce the $\mathrm{Fe}^{+3}$-TPTZ to $\mathrm{Fe}^{+2}$ complexes. Moreover, TPC is highly correlated $(r=0.59)$ with the antioxidant activity. Results also indicated a significant impact of heat treatment on the kinetics of antioxidant activity. Fresh samples, for instance, had a correlation coefficient of 0.81 while drying and blanched resulted in a decrease in correlation coefficient between TPC and antioxidant activity to 0.44 and 0.22 , respectively. In this regard, Chuah et al. [27] correlated the high total antioxidant capacity in walnut skin to its high levels of phenolic acids and tannins. On the same manner, due to the heat treatment, Açar et al. [28] indicated that the inactivation of prooxidant enzyme resulted in decreasing the antioxidant activity of cashew nut extracts.

$\mathrm{DPPH}(\%)$ of fresh treatment had the lowest $\mathrm{IC}_{50}$ indicating a significant effect of processing, namely, blanching and drying on the DPPH inhibition with the exception of avocado and orange peel. For instance, avocado seeds $\mathrm{IC}_{50}$ increased from $17.8 \%$ of fresh to $28.2,21.6$, and 52.5 for freezed, blanched, and dried treatments, respectively. Similarly, $\mathrm{IC}_{50}$ increased from 20.0 of fresh to $39.8 \%$ of dried pineapple peel and from 6.5 to $15.0 \%$ for pomegranate skin of fresh and dried treatments, respectively. Processing of fruit by-products seems to be the detrimental preservation technique. Processing and cooking of fruit by-products may have affected the proanthocyanidin content suggesting proanthocyanidins degradation during the drying process. Moreover, heat treatment may have resulted in the formation of highly polymerised compounds and thus affected the extraction of bioactive compounds [29]. Freezing, on the contrary seemed to be the least harmful having DPPH retention values. It is worth indicating here that DPPH inhibition of avocado peel results in an increase in DPPH with the heat treatment, while heat treatment had no impacts on the DPPH of orange peel. Our results are in agreement with Barth et al. [14] who indicate that boiling, pressure, and microwave cooking, baking, and frying at several timetemperature combinations were reported to reduce the radical scavenging activities of vegetables. On the same manner, Randhir et al. [24] reported that blanching significantly reduced DPPH inhibition activity in carrots. However, the authors reported a limited effect of blanching on the reducing power activity.

Table 2 presents a comparison of the average bioactive compounds and antioxidant activity of fruit by-products as affected by processing. The ANOVA indicated a significant 
TABLE 2: Average flavonoid content $(\mathrm{mg} / 100 \mathrm{~g})$, phenolic content $(\mathrm{mg} / 100 \mathrm{~g})$, reducing power $(0.1 \mathrm{~g} / 100 \mathrm{ml})$, and DPPH inhibition (\%) of dried, blanched, freezed, and fresh avocado peel, avocado seeds, kiwi fruit, orange peel, pineapple peel, and pomegranate skin.

\begin{tabular}{|c|c|c|c|c|c|}
\hline Status & Fruit & TFC $(\mathrm{mg} / 100 \mathrm{~g})^{1}$ & TPC (mg/100 g) & FRAP $(0.1 \mathrm{mg} / 100 \mathrm{ml})$ & $\mathrm{IC}_{50}(\%)$ \\
\hline \multirow{6}{*}{ Dried } & Avocado peel & $136.9^{c}$ & $1,017.2^{\mathrm{e}}$ & $93.6^{c}$ & $14.5^{\mathrm{d}}$ \\
\hline & Avocado seed & $54.1^{\mathrm{d}}$ & $5,973.0^{\mathrm{b}}$ & $152.2^{\mathrm{b}}$ & $52.5^{\mathrm{a}}$ \\
\hline & Kiwi fruit & $10.6^{\mathrm{f}}$ & $4,571.9^{c}$ & $59.9^{\mathrm{d}}$ & $32.1^{\mathrm{c}}$ \\
\hline & Orange peel & $380.0^{\mathrm{b}}$ & $4,232.3^{c}$ & $177.7^{\mathrm{a}}$ & $27.7^{\mathrm{c}}$ \\
\hline & Pineapple peel & $18.8^{\mathrm{e}}$ & $1,342.8^{\mathrm{d}}$ & $42.6^{\mathrm{e}}$ & $15.0^{\mathrm{d}}$ \\
\hline & Pomegranate skin & $862.5^{\mathrm{a}}$ & $6,138.2^{\mathrm{a}}$ & $93.6^{\mathrm{c}}$ & $39.8^{\mathrm{b}}$ \\
\hline \multirow{6}{*}{ Blanched } & Avocado peel & $63.1^{\mathrm{c}}$ & $359.1^{\mathrm{f}}$ & $169.0^{\mathrm{a}}$ & $11.1^{\mathrm{f}}$ \\
\hline & Avocado seed & $45.4^{\mathrm{d}}$ & $4,958.6^{\mathrm{b}}$ & $147.9^{\mathrm{b}}$ & $21.6^{\mathrm{d}}$ \\
\hline & Kiwi fruit & $1.3^{\mathrm{f}}$ & $852.6^{\mathrm{d}}$ & $93.6^{\mathrm{e}}$ & $43.2^{\mathrm{b}}$ \\
\hline & Orange peel & $194.4^{\mathrm{b}}$ & $2,445.5^{\mathrm{c}}$ & $133.9^{c}$ & $38.8^{\mathrm{c}}$ \\
\hline & Pineapple peel & $13.1^{\mathrm{e}}$ & $733.4^{\mathrm{e}}$ & $32.3^{\mathrm{f}}$ & $19.8^{\mathrm{e}}$ \\
\hline & Pomegranate skin & $405.6^{\mathrm{a}}$ & $5,346.8^{\mathrm{a}}$ & $106.3^{\mathrm{d}}$ & $45.3^{\mathrm{a}}$ \\
\hline \multirow{6}{*}{ Freezed } & Avocado peel & $20.6^{\mathrm{d}}$ & $1,000.5^{\mathrm{c}}$ & $128.3^{\mathrm{b}}$ & $76.6^{\mathrm{a}}$ \\
\hline & Avocado seed & $33.8^{\mathrm{c}}$ & $1,268.6^{\mathrm{b}}$ & $128.2^{\mathrm{b}}$ & $17.8^{\mathrm{d}}$ \\
\hline & Kiwi fruit & $0.0^{\mathrm{e}}$ & $324.2^{\mathrm{e}}$ & $32.1^{\mathrm{d}}$ & $20.2^{\mathrm{C}}$ \\
\hline & Orange peel & $56.9^{\mathrm{b}}$ & $828.5^{\mathrm{d}}$ & $49.3^{\mathrm{c}}$ & $26.2^{\mathrm{b}}$ \\
\hline & Pineapple peel & $1.3^{\mathrm{e}}$ & $152.4^{\mathrm{f}}$ & $6.5^{\mathrm{e}}$ & $6.5^{\mathrm{e}}$ \\
\hline & Pomegranate skin & $478.8^{\mathrm{a}}$ & $6,454.4^{\mathrm{a}}$ & $173.5^{\mathrm{a}}$ & $20.0^{\mathrm{c}}$ \\
\hline \multirow{6}{*}{ Fresh } & Avocado peel & $14.4^{\mathrm{d}}$ & $2,466.8^{\mathrm{b}}$ & $149.2^{\mathrm{b}}$ & $55.6^{\mathrm{a}}$ \\
\hline & Avocado seed & $39.8^{\mathrm{c}}$ & $2,036.6^{\mathrm{c}}$ & $142.7^{\mathrm{c}}$ & $28.2^{\mathrm{d}}$ \\
\hline & Kiwi fruit & $1.3^{\mathrm{e}}$ & $331.8^{\mathrm{e}}$ & $28.5^{\mathrm{e}}$ & $30.0^{c}$ \\
\hline & Orange peel & $54.4^{\mathrm{b}}$ & $756.5^{\mathrm{d}}$ & $47.7^{\mathrm{d}}$ & $26.1^{\mathrm{e}}$ \\
\hline & Pineapple peel & $18.8^{\mathrm{d}}$ & $95.0^{\mathrm{f}}$ & $0.6^{\mathrm{f}}$ & $9.9^{\mathrm{f}}$ \\
\hline & Pomegranate skin & $504.4^{\mathrm{a}}$ & $6,909.8^{\mathrm{a}}$ & $166.6^{\mathrm{a}}$ & $47.8^{\mathrm{b}}$ \\
\hline
\end{tabular}

${ }^{1}$ Flavonoids content (quercetin equivalents (mg/100 g)), phenolic compounds (gallic acid equivalents (mg/100 g)), FRAP (ascorbic acid equivalent $(0.1 \mathrm{~g} / 100 \mathrm{ml})$ ), and $\mathrm{IC}_{50}$ (i.e., concentration of extract $(\mathrm{mg} / \mathrm{ml})$ needed to scavenge $50 \%$ of the DPPH radicals $(\mathrm{mg} / \mathrm{ml})$ ) within the same treatments (blanched, dried, freeze, and fresh) of different fruit by-products having different letters are significantly $(P<0.05)$ different according to the LSD.

difference $(P<0.05)$ between various processing methods on TPC, FRAP, TFC, and $\mathrm{IC}_{50}$ measurements of fruit byproducts (Table 3 ). Flavonoid content ranged from 10.6 to 862.5 , from 1.3 to 405.6 , from 0.0 to 478.8 , and from 1.3 to $504.4 \mathrm{mg} / 100 \mathrm{~g}$, while TPC ranged from 1017.2 to 6138.2 , from 359.1 to 5346.8 , from 152.4 to 6454.4 , and from 95.0 to $6909.8 \mathrm{mg} / 100 \mathrm{~g}$ of dried, blanched, freezed, and fresh fruit by-products, respectively. Results showed that pomegranate skin had the greatest $(P<0.05)$ TFC and TPC regardless of processing, while kiwifruit skin had the lowest TFC. Avocado peel had the lowest $(P<0.05)$ TPC of dried and blanched, while pineapple peel had the lowest $(P<0.05)$ TPC of freezed and fresh treatments.

According to their structure, phenolics (i.e., compounds that contain one or more phenol unit in their molecules) are classified into several phenolic acids, coumarins, flavonoids, stilbenes, lignans, lignins, and tannins [30]. More specifically, condensed tannins that are also known as proanthocyanidins are found in abundance in fruits and fruit products [31]. Koleckar et al. [32] reported a high level of tannin punicalagin in pomegranate juice $(1500-1900 \mathrm{mg} / \mathrm{L})$ and suggested greater levels in pomegranate peels. The authors have also detected and quantified the presence of anthocyanins, ellagic acid derivatives, and hydrolyzable tannins. Several authors have also linked proanthocyanidins to antioxidant properties including free radical scavengers and chelators of transition metals and have an inhibitory power of prooxidative enzymes $[29,33]$. More specifically,
Landete et al. [34] reported the presence of punicalagin in pomegranate husk that was comparable to that in pomegranate juice with punicalagin showing significant ferrous chelating activity and reducing power ability.

Our results are in agreement with Aloqbi et al. [35] who reported that avocado pulp is rich in flavonoids $(21.9 \pm 1.0 \mathrm{mg} / 100 \mathrm{~g}), \quad$ phenolic compounds $(410.2 \pm 69.0 \mathrm{mg} / 100 \mathrm{~g})$ and carotenoids $(0.815 \pm 0.201 \mathrm{mg} /$ $100 \mathrm{~g})$. The authors also indicate that avocado skin was reported of being superior to the pulp with $44.3 \pm 3.1 \mathrm{mg} /$ $100 \mathrm{~g}$ of flavonoids, $679.0 \pm 117.0 \mathrm{mg} / 100 \mathrm{~g}$ of total phenolics, and $2.585 \pm 0.117 \mathrm{mg} / 100 \mathrm{~g}$ of carotenoids, in addition to its TPC $(704.0 \pm 130.0 \mathrm{mg} / 100 \mathrm{~g})$, that is, mainly catechins, hydroxybenzoic acids, hydroxycinnamic acids, procyanidins, and flavanols $(47.97 \pm 2.69 \mathrm{mg} / 100 \mathrm{~g})$; avocado seeds were reported to contain a high level of $\alpha$-tocopherol $(5.36 \pm 1.77 \mathrm{mg} / 100 \mathrm{~g})$ and $\alpha$-tocotrienol, lutein, and $\beta$-carotene exhibiting its higher antioxidant activity $[35,36]$. As for pineapple peels, polyphenolic compounds were reported to be mainly catechin ( $58.51 \mathrm{mg} / 100 \mathrm{~g}$ dry extracts), epicatechin $(50.00 \mathrm{mg} / 100 \mathrm{~g})$, gallic acid $(31.76 \mathrm{mg} / 100 \mathrm{~g})$, and ferulic acid (19.50 mg/100 g) [2]. These polyphenolic compounds exhibit the antioxidant activity of the pineapple peels.

Our results also indicated significant variation $(P<0.05)$ between various bioactive compounds composition and antioxidant activity of fruits by-products. TFC and TPC variation between various fruits by-products was related to 
TABLE 3: Analysis of variance (ANOVA) of the total phenolic content (TPC), FRAP, total flavonoid content (TFC), and IC50 of fruit byproducts during blanching, drying, fresh, and freezing.

\begin{tabular}{|c|c|c|c|c|c|c|c|c|c|}
\hline \multirow{2}{*}{ Source of variation } & \multicolumn{9}{|c|}{ TPC (mg/100g) } \\
\hline & \multicolumn{2}{|l|}{ DF } & Sum of squares & Mean square & $F$ ratio & & Sum of squares & Mean square & $F$ ratio \\
\hline Model & 5 & & 54402892 & 10880578 & 17662.06 & & 52229606 & 10445921 & 19353.98 \\
\hline Error & 6 & Blanching & 3696 & 616.0425 & & Drying & 3238 & 539.73 & \\
\hline C. total & 11 & & 54406589 & & & & 52232844 & & \\
\hline Model & 5 & & 56644119 & 11328824 & 88131.41 & & 64447734 & 12889547 & 107250.9 \\
\hline Error & 6 & Freezing & 771 & 128.54468 & & Fresh & 721 & 120.1812 & \\
\hline C. total & 11 & & 56644890 & & & & 64448455 & & \\
\hline \multicolumn{10}{|c|}{ FRAP $(0.1 \mathrm{mg} / 100 \mathrm{ml})$} \\
\hline Model & 5 & & 30167.021 & 6033.4 & 6786.532 & & 17516.363 & 3503.27 & 10426.87 \\
\hline Error & 6 & Blanching & 5.334 & 0.89 & & Drying & 2.016 & 0.34 & \\
\hline C. total & 11 & & 30172.355 & & & & 17518.379 & & \\
\hline Model & 5 & & 43594.666 & 8718.93 & 65797.14 & & 51424.725 & 10284.9 & 139105.7 \\
\hline Error & 6 & Freezing & 0.795 & 0.13 & & Fresh & 0.444 & 0.073936 & \\
\hline C. total & 11 & & 43595.461 & & & & 51425.168 & & \\
\hline \multicolumn{10}{|c|}{ TFC (mg/100 g) } \\
\hline Model & 5 & & 355163.56 & 71032.7 & 28558.26 & & 1063844.1 & 212769 & 143843.7 \\
\hline Error & 6 & Blanching & 14.92 & 2.5 & & Drying & 8.9 & 1.479167 & \\
\hline C. total & 11 & & 355178.49 & & & & 1063852.9 & & \\
\hline Model & 5 & & 351479.17 & 70295.8 & 12854.1 & & 385470.96 & 77094.2 & 19001.39 \\
\hline Error & 6 & Freezing & 32.81 & 5.5 & & Fresh & 24.34 & 4.1 & \\
\hline C. total & 11 & & 351511.98 & & & & 385495.31 & & \\
\hline \multicolumn{10}{|c|}{ IC50 (\%) } \\
\hline Model & 5 & & 1853.01 & 370.602 & 1822.633 & & 2252.3367 & 450.467 & 1001.039 \\
\hline Error & 6 & Blanching & 1.22 & 0.203 & & Drying & 2.7 & 0.45 & \\
\hline C. total & 11 & & 1854.23 & & & & 2255.0367 & & \\
\hline Model & 5 & & 6112.4967 & 1222.5 & 3526.44 & & 2685.1075 & 537.022 & 1682.574 \\
\hline Error & 6 & Freezing & 2.08 & 0.35 & & Fresh & 1.915 & 0.319 & \\
\hline C. total & 11 & & 6114.5767 & & & & 2687.0225 & & \\
\hline
\end{tabular}

Significance at $P<0.05$. Prob $>F=0.0001$ for all treatments.

the chemical composition and structure variations of plants. For instance, the plant shell was indicated to accumulate the higher concentration of these compounds as the protection mechanism against ultraviolet radiation and/or a defense against pathogens and predators [37].

Table 2 also presents the reducing power and DPHH of fruit by-products during processing. Results showed that pomegranate skin had the greatest $(P<0.05)$ reducing power of fresh and freezed samples, while avocado seed and orange peel had the greatest $(P<0.05)$ power of the dried and blanched samples, respectively. Avocado peel had the lowest $\mathrm{IC}_{50}$ of heat-treated samples, while it had the greatest $(P<0.05)$ of fresh and freezed samples. These results indicated that due to the differences in bioactive compound types of various fruit by-products, it was expected that these compounds are influenced by processing conditions differently.

\section{Conclusion}

Fruit by-products flours were characterized in relation to the effect of processing on its bioactive compounds. Fruit by-products have significant amount of flavonoids and phenolic compounds and poses high reducing power and antioxidant activity. Drying, blanching, and freezing have significant impacts on bioactive compounds and antioxidant activity. Results suggest the possible utilization of the nonedible parts of avocado seed and skin, kiwifruit skin, pineapple peel, pomegranate skin, and orange peel as an inexpensive source of bioactive compounds. Nutritional value and antinutritional factors of fruits by-products are believed to be a fruitful research area with the use of fruits by-products produced expected to influence foods nutritional aspects.

\section{Data Availability}

The data used to support the findings of this study are available from the corresponding author upon request.

\section{Ethical Approval}

Human testing was not involved in this study.

\section{Consent}

Written informed consent was obtained from all study participants.

\section{Conflicts of Interest}

The authors declare that they have no conflicts of interest. 


\section{References}

[1] M. Nikoo, J. M. Regenstein, and H. Ahmadi Gavlighi, “Antioxidant and antimicrobial activities of (-)-Epigallocatechin3-gallate (EGCG) and its potential to preserve the quality and safety of foods," Comprehensive Reviews in Food Science and Food Safety, vol. 17, no. 3, pp. 732-753, 2018.

[2] S. G. Rudra, J. Nishad, N. Jakhar, and C. Kaur, "Food industry waste: mine of nutraceuticals," International Journal of Science, Environment and Technology, vol. 4, pp. 205-229, 2015.

[3] T. Li, P. Shen, W. Liu et al., "Major polyphenolics in pineapple peels and their antioxidant interactions," International Journal of Food Properties, vol. 17, no. 8, pp. 1805-1817, 2014.

[4] J. Silva Dias, "World importance, marketing and trading of vegetables," Acta Horticulturae, vol. 921, no. 921, pp. 153-169, 2011.

[5] A. C. De Camargo, C. M. M. Vidal, S. G. Canniatti-Brazaca, and F. Shahidi, "Fortification of cookies with peanut skins: effects on the composition, polyphenols, antioxidant properties, and sensory quality," Journal of Agricultural and Food Chemistry, vol. 62, no. 46, pp. 11228-11235, 2014.

[6] G. S. El-Baroty, M. F. Khalil, and S. H. A. Mostafa, "Natural antioxidant ingredient from by-products of fruits," American Journal of Agricultural and Biological Sciences, vol. 9, no. 3, pp. 311-320, 2014.

[7] L. Hui, L. He, L. Huan, L. XiaoLan, and Z. AiGuo, "Chemical composition of lavender essential oil and its antioxidant activity and inhibition against rhinitisrelated bacteria," African Journal of Microbiology Research, vol. 4, no. 4, pp. 309-313, 2010.

[8] R. Kiani, A. Arzani, and S. A. M. Mirmohammady Maibody, "Polyphenols, flavonoids, and antioxidant activity involved in salt tolerance in wheat, Aegilops cylindrica and their amphidiploids," Frontiers of Plant Science, vol. 12, Article ID 646221, 2021.

[9] B. Tohidi, M. Rahimmalek, and A. Arzani, "Essential oil composition, total phenolic, flavonoid contents, and antioxidant activity of Thymus species collected from different regions of Iran," Food Chemistry, vol. 220, pp. 153-161, 2017.

[10] S. Mercy, S. Muchira Banu, and I. Jenifer, "Application of different fruit peels formulations as a natural fertilizer for plant growth," International Journal of Scientific \& Technology Research, vol. 3, no. 1, pp. 300-307, 2014.

[11] N. A. Sagar, S. Pareek, S. Sharma, E. M. Yahia, and M. G. Lobo, "Fruit and vegetable waste: bioactive compounds, their extraction, and possible utilization," Comprehensive Reviews in Food Science and Food Safety, vol. 17, no. 3, pp. 512-531, 2018.

[12] B. N. P. Sah, T. Vasiljevic, S. McKechnie, and O. N. Donkor, "Effect of pineapple waste powder on probiotic growth, antioxidant and antimutagenic activities of yogurt," Journal of Food Science and Technology, vol. 53, no. 3, pp. 1698-1708, 2016.

[13] E. M. Yahia, "The contribution of fruits and vegetables to human health," in Fruit and Vegetable Phytochemicals: Chemistry, Nutritional Value and Stability, L. la Rosa, E. Alvarez-Parrilla, and G. Gonzalez-Aguilar, Eds., pp. 3-51, Wiley-Blackwell Publishing, Ames, Iowa, 2010.

[14] M. Barth, T. R. Hankinson, H. Zhuang, and F. Breidt, "Microbiological spoilage of fruits and vegetables," in Compendium of the Microbiological Spoilage of Foods and Beverages, Food Microbiology and Food Safety, W. H. Sperber and M. P. Doyle, Eds., Springer Science Business Media, LLC, Berlin, Germany, 2009.
[15] A. Jimenz-Monreal, L. Garcia-Diz, M. Martinez-Tome, M. Mariscal, and M. Murcia, "Influence of cooking methods on antioxidant activity of vegetables," Journal of Food Science, vol. 74, pp. 97-103, 2009.

[16] D. Phjimulyani, S. Raharjo, Y. Marsono, and U. Santoso, "The effect of blanching on antioxidant activity and glycosides of white saffron (Curcuma mangga Val.)," International Food Research Journal, vol. 19, pp. 617-621, 2012.

[17] G. Miliauskas, P. R. Venskutonis, and T. A. Van Beek, "Screening of radical scavenging activity of some medicinal and aromatic plant extracts," Food Chemistry, vol. 85, no. 2, pp. 231-237, 2004.

[18] K. Al-Ismail, M. Hamdan, and K. Al-Delaimy, "Antioxidant and anti Bacillus cereus activities of selected plant extracts," Jordan Journal of Agricultural Sciences, vol. 2, no. 2, pp. 64-74, 2006.

[19] I. F. F. Benzie and J. J. Strain, "The ferric reducing ability of plasma (FRAP) as a measure of "antioxidant power": the FRAP assay," Analytical Biochemistry, vol. 239, no. 1, pp. 70-76, 1996.

[20] D. Holland, K. Hatib, and I. Bar-Ya'akov, "Pomegranate: botany, horticulture, breeding," Horticultural Reviews, vol. 35, no. 2, pp. 127-191, 2009.

[21] G. Khaksar, S. Tabatabaei, A. Arzani, C. Ghobadi, and E. Ebrahimie, "Functional analysis of a pomegranate (punica granatum L.) MYB transcription factor involved in the regulation of anthocyanin biosynthesis," Iranian Journal of Biotechnology, vol. 13, no. 1, pp. 17-25, 2015.

[22] W. Brand-Williams, M. E. Cuvelier, and C. Berset, "Use of a free radical method to evaluate antioxidant activity," Lebensmittel-Wissenschaft und-Technologie- Food Science and Technology, vol. 28, no. 1, pp. 25-30, 1995.

[23] W. Wang, R. Terrell, and L. G. Bostic, "Antioxidant capacities, procyanidins and pigments in avocados of different strains and cultivars," Food Chemistry, vol. 122, no. 4, pp. 193-198, 2010.

[24] R. Randhir, Y.-I. Kwon, and K. Shetty, "Effect of thermal processing on phenolics, antioxidant activity and healthrelevant functionality of select grain sprouts and seedlings," Innovative Food Science \& Emerging Technologies, vol. 9, no. 3, pp. 355-364, 2008.

[25] M. M. Al-Dabbas, M. I. Saleh, and K. Al-Ismail, "Preservation methods impacted phenolic, flavonoid and carotenoid contents and antioxidant activities of carrots (D aucus carota L.)," Journal of Food Processing and Preservation, vol. 39, no. 6, pp. 1618-1625, 2015.

[26] G. A. Shaimaa, M. S. Mahmoud, M. R. Mohamed, and A. A. Emam, "Effect of heat treatment on phenolic and flavonoid compounds and antioxidant activities of some Egyptian sweet and chilli pepper," Natural Products Chemistry \& Research, vol. 4, no. 3, pp. 1-6, 2016.

[27] A. M. Chuah, Y.-C. Lee, T. Yamaguchi, H. Takamura, L.-J. Yin, and T. Matoba, "Effect of cooking on the antioxidant properties of coloured peppers," Food Chemistry, vol. 111, no. 1, pp. 20-28, 2008.

[28] Ö. Ç. Açar, V. Gökmen, N. Pellegrini, and V. Fogliano, "Direct evaluation of the total antioxidant capacity of raw and roasted pulses, nuts and seeds," European Food Research and Technology, vol. 229, no. 6, pp. 961-969, 2009.

[29] I. Kubo, N. Masuoka, T. J. Ha, and K. Tsujimoto, “Antioxidant activity of anacardic acids," Food Chemistry, vol. 99, no. 3, pp. 555-562, 2006.

[30] J. Serrano, R. Puupponen-Pimiä, A. Dauer, A.-M. Aura, and F. Saura-Calixto, "Tannins: current knowledge of food 
sources, intake, bioavailability and biological effects," Molecular Nutrition \& Food Research, vol. 53, no. S2, pp. S310S329, 2009.

[31] M. Naczk and F. Shahidi, "Phenolics in cereals, fruits and vegetables: occurrence, extraction and analysis," Journal of Pharmaceutical and Biomedical Analysis, vol. 41, no. 5, pp. 1523-1542, 2006.

[32] V. Koleckar, K. Kubikova, Z. Rehakova et al., "Condensed and hydrolysable tannins as antioxidants influencing the health," Mini-Reviews in Medicinal Chemistry, vol. 8, no. 5, pp. 436447, 2008.

[33] M. I. Gil, F. A. Tomás-Barberán, B. Hess-Pierce, D. M. Holcroft, and A. A. Kader, "Antioxidant activity of pomegranate juice and its relationship with phenolic composition and processing," Journal of Agricultural and Food Chemistry, vol. 48, no. 10, pp. 4581-4589, 2000.

[34] J. M. Landete, "Updated knowledge about polyphenols: functions, bioavailability, metabolism, and health," Critical Reviews in Food Science and Nutrition, vol. 52, no. 10, pp. 936-948, 2012.

[35] A. Aloqbi, U. Omar, M. Yousr, M. Grace, M. A. Lila, and N. Howell, "Antioxidant activity of pomegranate juice and punicalagin," Natural Science, vol. 8, no. 6, pp. 235-246, 2016.

[36] A. F. Vinha, J. Moreira, and S. V. P. Barreira, "Physicochemical parameters, phytochemical composition and antioxidant activity of the algarvian avocado (Persea americana mill.)," The Journal of Agricultural Sciences, vol. 5, no. 12, pp. 100-109, 2013.

[37] M. Flores, J. Ortiz-Viedma, A. Curaqueo et al., "Preliminary studies of chemical and physical properties of two varieties of avocado seeds grown in Chile," Journal of Food Quality, vol. 2019, Article ID 3563750, 11 pages, 2019. 